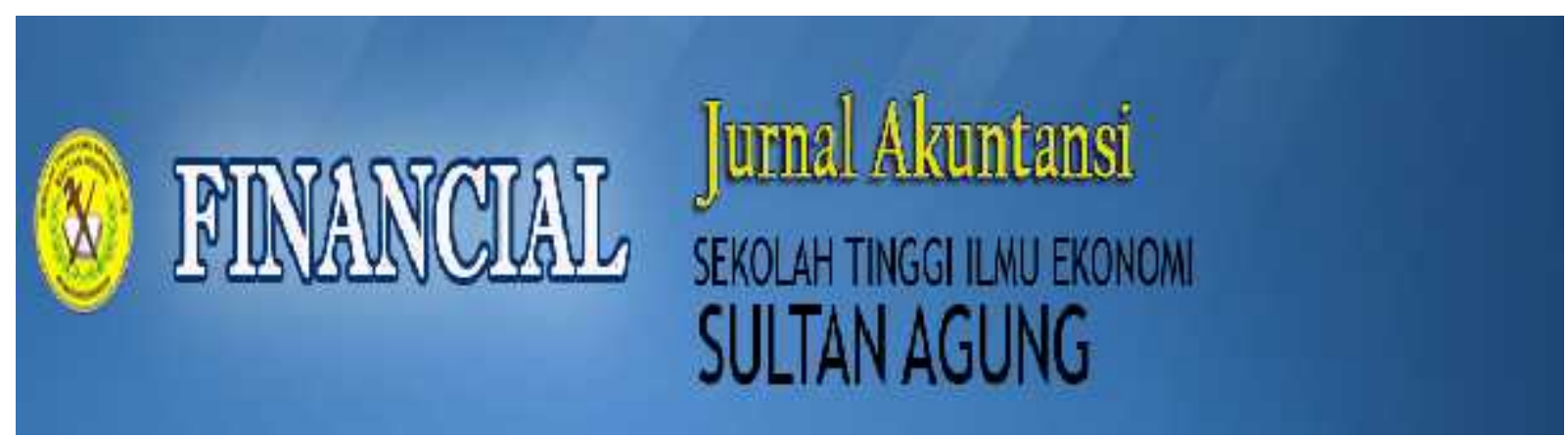

\title{
ANALISIS PERBANDINGAN KINERJA KEUANGAN PT MULTISTRADA ARAH SARANA, Tbk DAN PT GOODYEAR INDONESIA, Tbk YANG TERDAFTAR DI BURSA EFEK INDONESIA DENGAN MENGGUNAKAN METODE DU PONT SYSTEM
}

\author{
Oleh : \\ Rizki Fadilla Nasution \\ S1 Akuntansi \\ Jubi, Ady Inrawan, Astuti
}

Abstrak

Tujuan penulis dalam penelitian ini adalah: 1. Untuk mengetahui gambaran kinerja keuangan PT Multistrada Arah Sarana, Tbk dan PT Goodyear Indonesia, Tbk yang terdaftar di Bursa Efek Indonesia dengan menggunakan Metode Du Pont System. 2. Untuk mengetahui faktor-faktor apa yang menyebabkan perbedaan kinerja keuangan PT Multistrada Arah Sarana, Tbk dan PT Goodyear Indonesia, Tbk yang terdaftar di Bursa Efek Indonesia dengan menggunakan Metode Du Pont System. Penelitian penulis dilakukan dengan menggunakan teknik analisis deskriptif kualitatif, teknik analisis komparatif dan teknik analisis induktif.

Hasil dari penelitian ini disimpulkan 1. Kinerja keuangan PT Multistrada Arah Sarana, Tbk dikatakan kurang baikkarena kemampuan perusahaan dalam memperoleh laba dari penjualan, aset dan ekuitas menurun. 2. Kinerja keuangan PT Goodyear Indonesia, Tbk dikatakan baikkarena perusahaan mampu memperoleh laba dari segi penjualan, total aset dan ekuitas.3. Faktor yang menyebabkan perbedaan kedua perusahaan yaitu adanya beban-beban yaitu beban pokok penjualan, beban penjualan dan beban pajak.

Hasil analisis menyarankan agar kedua perusahaan diharapkan lebih meningkatkan penjualan dan mengurangi biaya-biaya yang merugikan bagi perusahaan agar mampu meningkatkan laba.

Kata Kunci : Analisis Du Pont System, Net Profit Margin, Asset Turnover, Return On Asset, Equity Multiplier, Return On Equity dan Kinerja Keuangan.

Abstract

The purpose of this research are : 1. to find out the financial performance of PT Multistrada Arah Sarana, Tbk and PT Goodyear Indonesia, Tbk listed on the Indonesia Stock Exchange using the Du Pont System Method. 2. to find out what factors cause differences in the financial performance of PT PT Multistrada Arah Sarana, Tbk and PT Goodyear Indonesia, Tbk listed on the Indonesia Stock Exchange using the Du Pont System Method. The author's research was conducted using qualitative descriptive analysis techniques, comparative analysis techniques and inductive analysis techniques.

This result of this research be conclused as 1. The financial performance of PT Multistrada Arah Sarana, Tbk is said to be unfavorable because of the company's ability to profit from sales, assets and equity decreases. 3. Factors that cause the differences between the two companies are the high cost of goods sold and the cost that cause losses to the company, accumulated invenory that reduces sales and company profits, the high total assets of total equity and increased share capital and additional capital causes companies to be unable restore equity.

The results of the analysis suggest that both companies are expected to further increase sales and reduce costs that are detrimental to the company in order to be able to increase profits.

Keywords: Analysis of Du Pont Sytem, Net Profit Margin, Asset Turnover, Return On Asset, Equity Multiplier, Return On Equity and Financial Performance. 


\section{PENDAHULUAN}

\subsection{Latar Belakang Masalah}

Kinerja keuangan merupakan pencapaian oleh manajemen keuangan dalam mencapai tujuan perusahaan agar perusahaan menghasilkan keuntungan dan dapat meningkatkan nilai perusahaan. Ada beberapa teknik analisis yang digunakan dalam menganalisis laporan keuangan diantaranya adalah Du Pont System. Analisis Du Pont merupakan salah satu pendekatan terpadu terhadap analisis rasio keuangan. Melalui analisis ini perusahaan dapat menilai kinerja keuangan dengan melihat efektivitas penggunaan aset dalam memperoleh laba bersih, sehingga pada akhirnya perusahaan dapat mengambil kebijaksanaan yang tepat atas perusahaannya.Dalam metode ini, yang menjadi fokus perhitungannya yaitu NPM (Net Profit Margin), ATO (Asset Turnover), ROA (Return on Asset), EM (Equity Multiplier) dan ROE (Return on Equity).

Tabel 1.1

Gambaran Return On Equity (ROE) PT Multistrada Arah Sarana, Tbk dan PT Goodyear Indonesia, Tbk yang Terdaftar di Bursa Efek Indonesia Tahun 2012-2017

\begin{tabular}{|c|c|c|}
\hline \multirow{2}{*}{ TAHUN } & \multicolumn{2}{|c|}{ ROE (Kali) } \\
\cline { 2 - 3 } & $\begin{array}{c}\text { PT Multistrada } \\
\text { Arah } \\
\text { Sarana, Tbk }\end{array}$ & $\begin{array}{c}\text { PT Goodyear } \\
\text { Indonesia, Tbk }\end{array}$ \\
\hline 2012 & 0,001 & 0,127 \\
\hline 2013 & 0,010 & 0,082 \\
\hline 2014 & 0,001 & 0,047 \\
\hline 2015 & $-0,078$ & $-0,002$ \\
\hline 2016 & $-0,020$ & 0,029 \\
\hline 2017 & $-0,024$ & $-0,017$ \\
\hline Rata-rata & $-\mathbf{0 , 0 1 8}$ & $\mathbf{0 , 0 4 4}$ \\
\hline
\end{tabular}

Sumber: Laporan Keuangan PT Multistrada Arah Sarana, Tbk dan PT Goodyear Indonesia, Tbk (Data diolah:2018)

Berdasarkan tabel 1.1, dapat dilihat keadaan kinerja keuangan PT Multistrada Arah Sarana, Tbk dan PT Goodyear Indonesia, Tbk yang terdaftar di Bursa Efek Indonesia selama periode 2012-2017 yang diukur dengan Return On Equity mengalami fluktuasi cenderung menurun. Dilihat dari rata-rata Return On Equity pada PT Multistrada Arah Sarana, Tbk sebesar -0,018 yang berarti ekuitas yang dimiliki PT Multistrada Arah Sarana, Tbk tidak mampu memperoleh laba. Sedangkan dilihat dari rata-rata Return On Equity PT Goodyear Indonesia, Tbk sebesar 0,044 yang berarti ekuitas yang dimiliki PT Goodyear Indonesia, Tbk mampu memperoleh laba.

\subsection{Rumusan Masalah}

1. Bagaimana gambaran kinerja keuangan PT

Multistrada Arah Sarana, Tbk dan PT Goodyear Indonesia, Tbk yang terdaftar di Bursa Efek Indonesia menggunakan metode Du Pont System.
2. Faktor-faktor apa yang menyebabkan perbedaan kinerja keuanganPT Multistrada Arah Sarana, Tbk dan PT Goodyear Indonesia, Tbk yang terdaftar di Bursa Efek Indonesia menggunakan metode Du Pont System.

\subsection{Tujuan Penelitian}

1. Untuk mengetahui gambaran kinerja keuangan PT Multistrada Arah Sarana, Tbk dan PT Goodyear Indonesia, Tbk yang terdaftar di Bursa Efek Indonesia menggunakan metode Du Pont System.

2. Untuk mengetahui faktor-faktor apa yang menyebabkan perbedaan kinerja keuangan PT Multistrada Arah Sarana, Tbk dengan PT Goodyear Indonesia, Tbk yang terdaftar di Bursa Efek Indonesia menggunakan metode Du Pont System.

\subsection{Metode Penelitian}

Penelitian ini menggunakan data kualitatif dan kuantitatif. Desain penelitian ini adalah penelitian kepustakaan (library research). Teknik analisa data yang digunakan adalah teknik analisis deskriptif kualitatif, teknik analisis komparatif dan teknik analisis induktif.

\section{LANDASAN TEOR}

\subsection{Akuntansi}

Akuntansi merupakan alat komunikasi dalam suatu dunia usaha, dimana peranan disetiap akuntansi yang berlaku di suatu perusahaan itu berbeda. Pengertian akuntansi menurut Rudianto (2009:4), sebuah sistem informasi yang menghasilkan informasi keuangan kepada pihak-pihak yang berkepentingan mengenai kegiatan ekonomi dan kondisi suatu perusahaan. Menurut Mursyidi (2010:19), tujuan utama akuntansi adalah menyajikan informasi ekonomi dari suatu entitas kepada pihak-pihak yang berkepentingan. Sedangkan menurut Hery (2017:1), tujuan akuntansi secara keseluruhan adalah memberikan informasi yang dapat digunakan dalam pengembalian keputusan.

\subsection{Analisa Laporan Keuangan}

Menurut Astuti (2004:29), analisis laporan keuangan adalah segala sesuatu yang menyangkut penggunaan informasi akuntansi untuk membuat keputusan bisnis dan investasi. Sedangkan menurut Najmudin (2011:64), analisis laporan keuangan berarti suatu proses penguraian data (informasi) yang terdapat dalam laporan keuangan menjadi komponenkomponen tersebut tersendiri, menelaah setiap komponen, dan memelajari hubungan antar komponen tersebut menggunakan teknik analisis tertentu dengan tujuan diperolehnya pemahaman yang tepat dan gambaran yang komprehensif tentang informasi tersebut. 
Sementara menurut Subramanyam dan John (2010:4), analisis laporan keuangan adalah aplikasi dari alat dan teknik analisis untuk laporan keuangan bertujuan umum dan datadata yang berkaitan untuk menghasilkan estimasi dan kesimpulan yang bermanfaat dalam analisis bisnis.

\subsection{Analisis Kinerja Keuangan}

Kinerja keuangan merupakan gambaran pencapaian dari suatu perusahaan. Kinerja keuangan dapat diperoleh dari informasi yang terdapat di laporan keuangan. Menurut Hery (2017:480), kinerja keuangan adalah sebagai pengukuran atas kontribusi yang dapat diberikan oleh suatu bagian (divisi) bagi pencapaian tujuan perusahaan. Menurut Brigham dan Joel (2010:359), rasio profitabilitas mencerminkan hasil ahir dari kinerja keuangan dan keputusan operasional. Karena profitabilitas merupakan sekelompok rasio yang menunjukkan kombinasi dari pengaruh likuiditas, manajemen aktiva, dan utang terhadap hasil operasi.

Sedangkan menurut Rudianto (2013:189), kinerja keuangan merupakan hasil atau prestasi yang telah dicapai oleh manajemen perusahaan dalam menjalankan fungsinya mengelola aktiva perusahaan secara efektif selama periode tertentu.

\subsection{Analisis Du Pont System}

Analisis Du Pont merupakan salah satu cara untuk mengukur kinerja keuangan perusahaan. Menurut Brigham dan Joel (2010:153), Du Pont System merupakan rumus yang menunjukkan tingkat pengembalian aktiva yang dapat diperoleh dari perkalian laba bersih (net profit margin) dengan perputaran total aset (total assets). Menurut Keown, et. al. (2008:88), Du Pont System adalah suatu metode yang digunakan untuk menganalisis profitabilitas perusahaan dan tingkat pengembalian ekuitas.

Menurut Mamduh dan Halim (2016:86), Du Pont System adalah analisis yang memisahkan profitabilitas dengan pemanfaatan aset (asset utilization). Analisis ini menggabungkan tiga jenis rasio di dalamnya yaitu ROA, profit margin, dan perputaran aktiva.

\subsection{Analisis Kinerja Keuangan dengan}

Metode Du Pont System Perusahaan

Menurut Brigham dan Joel (2010:146), rasio profitabilitas mencerminkan hasil ahir dari kebijkan keuangan dan keputusan operasional. Karena profitabilitas merupakan sekelompok rasio yang menunjukkan kombinasi dari pengaruh likuiditas, manajemen aktiva, dan utang terhadap hasil operasi. Oleh karena itu, perlu dilakukan analisis rasio profitabilitas pada perusahaan untuk melihat sejauh mana perusahaan melakukan efektivitas pengelolaan manajemen dan keuangan. Dengan meningkatnya profitabilitas pada perusahaan maka perusahaan akan seakin baik dalam menghasilkan laba sehinggga kinerja keuangan perusahaan dianggap berhasil.

\section{PEMBAHASAN}

\subsection{Analisis}

3.1.1. Analisis Kinerja Keuangan PT Multistrada Arah Sarana, Tbk dengan Metode Du Pont System

\section{Net Profit Margin}

Berikut hasil databulasi data menghitung net profit margin PT Multistrada Arah Sarana, Tbk yang terdaftar di Bursa Efek Indonesia pada Tabel 3.1

Tabel 3.1

Net Profit Margin PT Multistrada Arah Sarana,

Tbk yang terdaftar di Bursa Efek Indonesia tahun

\begin{tabular}{|c|c|}
\hline \multicolumn{2}{|c|}{$\mathbf{2 0 1 2 - 2 0 1 7}$} \\
\hline Tahun & Net Profit Margin \\
\hline 2012 & 0,001 \\
\hline 2013 & 0,011 \\
\hline 2014 & 0,002 \\
\hline 2015 & $-0,113$ \\
\hline 2016 & $-0,029$ \\
\hline 2017 & $-0,029$ \\
\hline Nilai Maksimum & $\mathbf{0 , 0 1 1}$ \\
\hline Nilai Minimum & $\mathbf{- 0 , 1 1 3}$ \\
\hline Rata-rata & $\mathbf{- 0 , 0 2 6}$ \\
\hline
\end{tabular}

Sumber : Data diolah (2018)

Berdasarkan Tabel 3.1, net profit margin PT Multistrada Arah Sarana, Tbk yang terdaftar di Bursa Efek Indonesia selama tahun penelitian berfluktuasi cenderung menurun tiap tahunnya. Net profit margin mengalami penurunan pada tahun 2015

\section{Asset Turnover}

Berikut hasil databulasi data menghitung Asset Turnover PT Multistrada Arah Sarana, Tbk yang terdaftar di Bursa Efek Indonesia pada Tabel 3.2

Tabel 3.2

Asset Turnover PT Multistrada Arah Sarana, Tbk yang terdaftar di Bursa Efek Indonesia tahun 2012-2017

\begin{tabular}{|c|c|}
\hline Tahun & Asset Turnover \\
\hline 2012 & 0,514 \\
\hline 2013 & 0,515 \\
\hline 2014 & 0,455 \\
\hline 2015 & 0,396 \\
\hline 2016 & 0,377 \\
\hline 2017 & 0,427 \\
\hline Nilai Maksimum & $\mathbf{0 , 5 1 5}$ \\
\hline Nilai Minimum & $\mathbf{0 , 3 7 7}$ \\
\hline Rata-rata & $\mathbf{0 , 4 4 7}$ \\
\hline
\end{tabular}

Sumber : Data Diolah (2018)

Berdasarkan Tabel 3.2, asset turnover PT Multistrada Arah Sarana, Tbk yang terdaftar di 
Bursa Efek Indonesia selama tahun penelitian berfluktuasi cenderung menurun tiap tahunnya.

\section{Return On Asset}

Berikut hasil databulasi data menghitung return on asset PT Multistrada Arah Sarana, Tbk yang terdaftar di Bursa Efek Indonesia pada Tabel 3.3

Tabel 3.3

Return On Asset PT Multistrada Arah Sarana, Tbk yang terdaftar di Bursa Efek Indonesia tahun 2012-2017

\begin{tabular}{|c|c|}
\hline Tahun & Return On Asset \\
\hline 2012 & 0,001 \\
\hline 2013 & 0,006 \\
\hline 2014 & 0,001 \\
\hline 2015 & $-0,045$ \\
\hline 2016 & $-0,011$ \\
\hline 2017 & $-0,012$ \\
\hline Nilai Maksimum & $\mathbf{0 , 0 0 6}$ \\
\hline Nilai Minimum & $\mathbf{- 0 , 0 4 5}$ \\
\hline Rata-rata & $\mathbf{- 0 , 0 1 0}$ \\
\hline
\end{tabular}

Sumber : Data Diolah (2018)

Berdasarkan Tabel 4, Return On Asset PT Multistrada Arah Sarana, Tbk yang terdaftar di Bursa Efek Indonesia selama tahun penelitian berfluktuasi cenderung menurun tiap tahunnya. Return On Asset mengalami penurunan pada tahun 2015.

\section{Equity Multiplier}

Berikut hasil databulasi data menghitung Equity Multiplier PT Multistrada Arah Sarana, Tbk yang terdaftar di Bursa Efek Indonesia pada Tabel 3.4

Tabel 3.4

Equity Multiplier PT Multistrada Arah Sarana Tbk yang terdaftar di Bursa Efek Indonesia tahun

\begin{tabular}{|c|c|}
\hline \multicolumn{2}{|c|}{$\mathbf{2 0 1 2 - 2 0 1 7}$} \\
\hline Tahun & Equity Multiplier \\
\hline 2012 & 1.679 \\
\hline 2013 & 1,676 \\
\hline 2014 & 1,668 \\
\hline 2015 & 1,732 \\
\hline 2016 & 1,799 \\
\hline 2017 & 1,951 \\
\hline Nilai Maksimum & $\mathbf{1 , 9 5 1}$ \\
\hline Nilai Minimum & $\mathbf{1 , 6 6 8}$ \\
\hline Rata-rata & $\mathbf{1 , 7 5 1}$ \\
\hline
\end{tabular}

Sumber : Data Diolah (2018)

Berdasarkan Tabel 3.4, Equity multipier PT Multistrada Arah Sarana, Tbk yang terdaftar di Bursa Efek Indonesia mengalami fluktuasi cenderung meningkat.

\section{Return On Equity}

Berikut hasil databulasi data menghitung return on equity PT Multistrada Arah Sarana, Tbk yang terdaftar di Bursa Efek Indonesia pada Tabel 3.5

Tabel 3.5

Return On Equity PT Multistrada Arah Sarana, Tbk yang terdaftar di Bursa Efek Indonesia tahun 2012-2017

\begin{tabular}{|c|c|}
\hline Tahun & Return On Equity \\
\hline 2012 & 0,001 \\
\hline 2013 & 0,009 \\
\hline 2014 & 0,002 \\
\hline 2015 & $-0,078$ \\
\hline 2016 & $-0,020$ \\
\hline 2017 & $-0,023$ \\
\hline Nilai Maksimum & $\mathbf{0 , 0 0 9}$ \\
\hline Nilai Minimum & $\mathbf{- 0 , 0 7 8}$ \\
\hline Rata-rata & $\mathbf{- 0 , 0 1 8}$ \\
\hline
\end{tabular}

Sumber : Data Diolah (2018)

Berdasarkan Tabel 3.5, Return On Equity PT Multistrada Arah Sarana, Tbk yang terdaftar di bursa Efek Indonesia mengalami fluktuasi cenderung menurun tiap tahunnya. Return On Equity mengalami penurunan pada tahun 2015.

\subsubsection{Analisis Kinerja Keuangan PT Goodyear} Indonesia, Tbk dengan Metode Du Pont System

\section{Net Profit Margin}

Pada uraian di bawah ini dapat dilihat net profit margin PT Goodyear Indonesia, Tbk yang terdaftar di Bursa Efek Indonesia pada Tabel 3.6

Tabel 5.6

Net Profit Margin PT Goodyear Indonesia, Tbk yang terdaftar di Bursa Efek Indonesia tahun 2012-2017

\begin{tabular}{|c|c|}
\hline \multicolumn{2}{|c|}{ 2012-2017 } \\
\hline 2012 & Net Profit Margin \\
\hline 2013 & 0,033 \\
\hline 2014 & 0,025 \\
\hline 2015 & 0,017 \\
\hline 2016 & $-0,001$ \\
\hline 2017 & 0,011 \\
\hline Nilai Maksimum & $-0,006$ \\
\hline Nilai Minimum & $\mathbf{0 , 0 3 3}$ \\
\hline Rata-rata & $\mathbf{- 0 , 0 0 6}$ \\
\hline
\end{tabular}

Sumber : Data Diolah (2018)

Berdasarkan Tabel 3.6, net profit margin PT Goodyear Indonesia, Tbk yang terdaftar di Bursa Efek Indonesia mengalami fluktuasi cenderung menurun tiap tahunnya. Net Profit Margin mengalami penurunan di tahun 2017.

\section{Asset Turnover}

Pada uraian di bawah ini dapat dilihat asset turnover PT Goodyear Indonesia, Tbk yang terdaftar di Bursa Efek Indonesia pada Tabel 3.7 .

Tabel 3.7

Asset Turnover PT Goodyear Indonesia, Tbk yang terdaftar di Bursa Efek Indonesia tahun 2012-2017

\begin{tabular}{|c|c|}
\hline Tahun & Asset Turnover \\
\hline 2012 & 1,641 \\
\hline 2013 & 1,660 \\
\hline 2014 & 1,281 \\
\hline 2015 & 1,294 \\
\hline 2016 & 1,369 \\
\hline 2017 & 1,303 \\
\hline Nilai Maksimum & $\mathbf{1 , 6 6 0}$ \\
\hline Nilai Minimum & $\mathbf{1 , 2 8 1}$ \\
\hline Rata-rata & $\mathbf{1 , 4 2 5}$ \\
\hline
\end{tabular}

Sumber : Data Diolah (2018) 
Berdasarkan Tabel 3.7, Asset Turnover PT Goodyear Indonesia, Tbk yang terdafar di Bursa Efek Indonesia mengalami fluktuasi cenderung menurun tiap tahunnya.

\section{Return On Assets}

Pada uraian di bawah ini dapat dilihat return on asset PT Goodyear Indonesia, Tbk yang terdaftar di Bursa Efek Indonesia pada Tabel 3.8

Tabel 3.8

Return On Asset PT Goodyear Indonesia, Tbk yang terdaftar di Bursa Efek Indonesia tahun 2012-2017

\begin{tabular}{|c|c|}
\hline Tahun & Return On Asset \\
\hline 2012 & 0,054 \\
\hline 2013 & 0,042 \\
\hline 2014 & 0,022 \\
\hline 2015 & $-0,001$ \\
\hline Tahun & Return On Asset \\
\hline 2016 & 0,015 \\
\hline 2017 & $-0,008$ \\
\hline Nilai Maksimum & $\mathbf{0 , 0 5 4}$ \\
\hline Nilai Minimum & $\mathbf{- 0 , 0 0 8}$ \\
\hline Rata-rata & $\mathbf{0 , 0 2 1}$ \\
\hline
\end{tabular}

Sumber : Data Diolah (2018)

Berdasarkan Tabel 3.8, return on asset PT Goodyear Indonesia, Tbk yang terdaftar di Bursa Efek Indonesia mengalami fluktuasi cenderung menurun tiap tahunnya. Penurunan terjadi di tahun 2017.

\section{Equity Multiplier}

Pada uraian di bawah ini dapat dilihat equity multiplier PT Goodyear Indonesia, Tbk yang terdaftar di Bursa Efek Indonesia pada Tabel 3.9 .

Tabel 3.9

Equity Multiplier PT Goodyear Indonesia, Tbk yang terdaftar di Bursa Efek Indonesia tahun 2012-2017

\begin{tabular}{|c|c|}
\hline \multicolumn{2}{|c|}{$-61 .-211$} \\
\hline Tahun & Equity Multiplier \\
\hline 2012 & 2,350 \\
\hline 2013 & 1,975 \\
\hline 2014 & 2,168 \\
\hline 2015 & 2,151 \\
\hline 2016 & 2,005 \\
\hline 2017 & 2,310 \\
\hline Nilai Maksimum & 2,350 \\
\hline Nilai Minimum & 1,975 \\
\hline Rata-rata & 2,160 \\
\hline
\end{tabular}

Sumber : Data Diolah (2018)

Berdasarkan Tabel 3.9, equity multiplier PT Goodyear Indonesia, Tbk yang terdaftar di Bursa Efek Indonesia mengalami fluktuasi cenderung menurun tiap tahunnya.

\section{Return On Equity}

Pada uraian di bawah ini dapat dilihat return on equity PT Goodyear Indonesia, Tbk yang terdaftar di Bursa Efek Indonesia pada Tabel 3.10

$$
\text { Tabel 5.10 }
$$

Return On Equity PT Goodyear Indonesia, Tbk yang terdaftar di Bursa Efek Indonesia tahun 2012-2017

\begin{tabular}{|c|c|}
\hline Tahun & Return On Equity \\
\hline 2012 & 0,127 \\
\hline 2013 & 0,082 \\
\hline 2014 & 0,047 \\
\hline 2015 & $-0,003$ \\
\hline 2016 & 0,030 \\
\hline 2017 & $-0,018$ \\
\hline Nilai Maksimum & 0,127 \\
\hline Nilai Minimum & $-0,018$ \\
\hline Rata-rata & 0,044 \\
\hline
\end{tabular}

Sumber : Data Diolah (2018)

Berdasarkan Tabel 3.10, return on equity PT Goodyear Indonesia, Tbk yang terdaftar di Bursa Efek Indonesia mengalami fluktuasi tiap tahunnya. Penurunan terjadi di tahun 2017.

\subsubsection{Analisis Perbandingan Return On Equity} PT PT Multistrada Arah Sarana, Tbk dengan PT Goodyear Indonesia, Tbk dengan Metode Du Pont System

Pada Tabel 3.11 menunjukkan gambaran return on equity dengan Du Pont System PT Multistrada Arah Sarana, Tbk dan PT Goodyear Indonesia, Tbk yang terdaftar di Bursa Efek Indonesia tahun 20122017 yaitu sebagai berikut:

Tabel 3.11

Gambaran Return On Equity PT Multistrada Arah Sarana, Tbk dan PT Goodyear Indonesia, Tbk

\begin{tabular}{|c|c|c|}
\hline \multirow{2}{*}{ TAHUN } & \multicolumn{2}{|c|}{ Return On Equity } \\
\cline { 2 - 3 } & $\begin{array}{c}\text { PT Multistrada } \\
\text { Arah Sarana, Tbk }\end{array}$ & $\begin{array}{c}\text { PT Goodyear } \\
\text { Indonesia, Tbk }\end{array}$ \\
\hline 2012 & 0,001 & 0,127 \\
\hline 2013 & 0,009 & 0,083 \\
\hline 2014 & 0,002 & 0,047 \\
\hline 2015 & $-0,078$ & $-0,003$ \\
\hline 2016 & $-0,02$ & 0,03 \\
\hline 2017 & $-0,024$ & $-0,018$ \\
\hline Rata-Rata & $-\mathbf{0 , 0 1 8}$ & $\mathbf{0 , 0 4 4}$ \\
\hline Sumber:
\end{tabular}

Sumber : Data Diolah (2018)

Berdasarkan Tabel 3.11, dilihat dari rata-rata return on equity dapat disimpulkan bahwa kemampuan kedua perusahaan dalam memperoleh profit, PT Goodyear Indonesia, Tbk lebih baik karena perusahaan mampu menghasilkan laba dari segi penggunaan ekuitas dibandingkan PT Multistrada Arah Sarana, Tbk yang perusahaannya tidak mampu menghasilkan laba dari segi penggunaan ekuitas.

\subsection{Evalausi}

\subsubsection{Evaluasi Kinerja Keuangan PT} Multistrada Arah Sarana, Tbk dengan Metode Du Pont System

\section{Net Profit Margin}

Dari hasil analisis net profit margin PT Multistrada Arah Sarana, Tbk yang terdaftar di Bursa Efek Indonesia perusahaan mengalami fluktuasi cenderung menurun tiap tahunnya. ini disebabkan oleh adanya beban pokok penjualan yang tinggi serta adanya biaya-biaya lain yang mengakibatkan kerugian pada perusahaan, berupa beban penjualan dan distribusi, beban umum dan administrasi, 
beban operasi lain, pajak atas penghasilan bunga dan beban keuangan.

\section{Asset Turnover}

Dari hasil analisis asset turnover PT Multistrada Arah Sarana, Tbk yang terdaftar di Bursa Efek Indonesia perusahaan mengalami fluktuasi cenderung menurun tiap tahunnya. Ini disebabkan oleh penjualan ke pasar Amerika mengalami penurunan karena tertundanya proyek ban offtake (perjanjian untuk pembelian dan penjualan jangka panjang selama periode tertentu) serta melemahnya mata uang Rupiah terhadap Dolar AS membuat penjualan dalam negeri mengalami penurunan sementara dalam Rupiah mengalami peningkatan. Perusahaan diharapkan untuk meningkatkan kepuasaan pelanggan dengan cara meningkatkan kualitas produk dari penjualan.

\section{Return On Assets}

Dari hasil analisis return on assets PT Multistrada Arah Sarana, Tbk yang terdaftar di Bursa Efek Indonesia perusahaan mengalami fluktuasi cenderung menurun tiap tahunnya. Ini disebabkan oleh aset yang meningkat dikarenakan persediaan menumpuk yang mengurangi penjualan sehingga mengurangi laba perusahaan.

\section{Equity Multiplier}

Dari hasil analisis equity multiplier PT Multistrada Arah Sarana, Tbk yang terdaftar di Bursa Efek Indonesia perusahaan mengalami fluktuasi cenderung meningkat tiap tahunnya. EM yang tinggi dikarenakan total aset yang meningkat dari total ekuitas. Total aset yang meningkat disebabkan karena adanya penumpukan pada persediaan yang mengurangi penjualan dan mengurangi laba.

\section{Return On Equity}

Dari hasil analisis return on equity PT Multistrada Arah Sarana, Tbk yang terdaftar di Bursa Efek Indonesia perusahaan mengalami fluktuasi cenderung menurun tiap tahunnya. ROE yang menurun dilihat juga dari ROA dan NPM yang menurun serta EM meningkat. Hal ini berarti kemampuaan perusahaan dalam memperoleh laba dari penjualan dan total aset menurun serta besarnya aset yang diperoleh dari ekuitas.

\subsubsection{Evaluasi Kinerja Keuangan PT Goodyear Indonesia, Tbk dengan Metode Du Pont System \\ 1. Net Profit Margin}

Dari hasil analisis net profit margin PT Goodyear Indonesia, Tbk yang terdaftar di Bursa Efek Indonesia perusahaan mengalami fluktuasi cenderung menurun tiap tahunnya. Ini disebabkan oleh penjualan yang mengalami kenaikan disebabkan oleh kenaikan harga jual akibat kenaikan harga pasar bahan baku, beban pokok penjualan yang mengalami kenaikan disebabkan kenaikan signifikan dan upah tenaga kerja, biaya penjualan yang disebabkan kenaikan biaya angkut dan perjalanan serta biaya-biaya lain yang mengakibatkan kerugian pada perusahaan.

\section{Asset Turnover}

Dari hasil analisis asset turnover PT Goodyear Indonesia, Tbk yang terdaftar di Bursa Efek Indonesia perusahaan mengalami fluktuasi cenderung menurun tiap tahunnya. Ini disebabkan oleh tingginya penjualan dari total aset yang menunjukkan efesiensi perusahaan mengelola asetnya dalam melakukan penjualan. Penjualan yang meningkat akan meningkatkan laba pada perusahaan.

\section{Return On Assets}

Dari hasil analisis return on asset PT Goodyear Indonesia, Tbk yang terdaftar di Bursa Efek Indonesia perusahaan mengalami fluktuasi cenderung menurun tiap tahunnya. Dilihat dari rata-rata, perusahaan mampu memperoleh laba dari total aset. Laba yang diperoleh perusahaan dilihat dari kemampuan perusahaan menghasilkan penjualan dari aset sehingga dari penjualan mampu memperoleh laba.

\section{Equity Multiplier}

Dari hasil analisis equity multiplier PT Goodyear Indonesia, Tbk yang terdaftar di Bursa Efek Indonesia perusahaan mengalami fluktuasi cenderung menurun. EM yang menurun disebabkan peningkatan total aset dari total ekuitas yang menunjukkan seberapa besar aset diperoleh oleh ekuitas. Total aset yang meningkat disebabkan oleh terlalu banyaknya dana pada kas perusahaan

\section{Return On Equity}

Dari hasil analisis return on equity PT Goodyear Indonesia, Tbk yang terdaftar di Bursa Efek Indonesia perusahaan mengalami fluktuasi cenderung menurun tiap tahunnya. Dilihat dari rata-rata perusahaan mampu memperoleh laba dari segi ekuitas dan dilihat dari ROA dan NPM yang mampu memperoleh laba dari penjualan dan aset perusahaan serta besarnya aset yang diperoleh dari ekuitas.

\subsubsection{Evaluasi Perbandingan Return On Equity} PT Multistrada Arah Sarana, Tbk dengan PT Goodyear Indonesia, Tbk dengan Metode Du Pont System

Dari hasil anaisis perbandingan return on equity kedua perusahaan yaitu pada PT Multistrada Arah Sarana, Tbk dan PT Goodyear Indonesia, Tbk yang terdaftar di Bursa Efek Indonesia mengalami fluktuasi dan cenderung menurun. Dilihat dari kinerja keuangan kedua perusahaan dapat disimpulkan bahwa kemampuan kedua perusahaan yaitu PT Multistrada Arah Sarana, Tbk dan PT Goodyear Indonesia, Tbk dalam memperoleh profit, PT Goodyear Indonesia, Tbk lebih baik karena dilihat dari rata-rata perusahaan mampu memperoleh laba dari segi 
ekuitas karena dilihat juga dari ROA dan NPM yang mampu memperoleh laba. Sedangkan pada PT Multistrada Arah Sarana, Tbk, perusahaan dikatakan kurang baik, karena dari segi ekuitas yang dilihat dari ROA dan NPM yang menurun serta EM meningkat. Hal ini berarti kemampuan perusahaan dalam memperoleh laba dari penjualan dan total aset menurun.

\section{KESIMPULAN DAN SARAN}

\subsection{Kesimpulan}

Berdasarkan analisis dari penelitian yang penulis lakukan, serta dari data-data yang diperoleh dari hasil penelitian, maka terdapat beberapa hal yang dapat disimpulkan:

1. Kinerja keuangan pada PT Multistrada Arah Sarana, Tbk yang diukur dengan menggunakan metode Du Pont System berfluktuasi cenderung menurun dan dapat dikatakan kinerja keuangan perusahaan kurang baik karena kemampuan perusahaan dalam memperoleh laba dari penjualan dan total aset dan ekuitas menurun. Untuk hasil perhitungannya, Net Profit Margin, Return On Asset dan Return On Equity menurun namun Asset Turnover dan Equity Multiplier meningkat.

2. Kinerja keuangan pada PT Goodyear Indonesia, Tbk yang diukur dengan menggunakan metode Du Pont System berfluktuasi cenderung menurun namun kinerja keuangan perusahaan dikatakan baik karena perusahaan mampu memperoleh laba dari segi penjualan, total aset dan ekuitas. Untuk hasil perhitungannya, Net Profit Margin, Return On Asset dan Return On Equity menurun namun Asset Turnover dan Equity Multiplier meningkat.

3. Kinerja keuangan pada PT Multistrada Arah Sarana, Tbk dan PT Goodyear Indonesia, Tbk yang diukur dengan menggunakan metode Du Pont System keduanya berfluktuasi cenderung menurun. Hal ini disebabkan karena adanya beban-beban yaitu beban pokok penjualan, beban penjualan dan beban pajak.

\subsection{Saran}

Berdasarkan hasil analisis dan kesimpulan di atas, maka saran yang dapat diberikan penulis adalah sebagai berikut:

1. Pada PT Multistarada Arah Sarana, Tbk perusahaan sebaiknya mengurangi biayabiaya yang dapat merugikan perusahaan, meningkatkan kualitas produk penjualan agar mampu memperoleh laba yang diharapkan, perusahaan diharapkan memperbaiki dan meningkatkan laba dengan cara meningkatkan efesiensi dan efektivitas penggunaan aset atau harta yang dimiliki perusahaan.

2. Pada PT Goodyear Indonesia, Tbk perusahaan diharapkan tetap meningkatkan laba agar profitabilitas dapat ditingkatkan.

3. Kedua perusahaan diharapkan lebih meningkatkan penjualan, serta mengurangi biaya-biaya yang merugikan bagi perusahaan.

4. Sehubungan dengan keterbatasan penulis masih terdapat kelemahan dalam menganalisis perbandingan kinerja keuangan PT Multistrada Arah Sarana, Tbk dan PT Goodyear Indonesia, Tbk yang terdaftar di Bursa Efek Indonesia dengan Menggunakan Metode Du Pont System secara sempurna. Oleh karena itu, penulis berharap kepada peneliti selanjutnya utuk lebih menyempurnakan di masa yang akan datang.

\section{DAFTAR PUSTAKA}

Astuti, Dewi, 2004. Manajemen Keuangan Perusahaan. Jakarta: Ghalia Indonesia.

Brigham, Eugene F., dan Joel F. Houston. 2010. Dasar-Dasar Manejemen Keuangan, Buku Satu, Edisi Sebelas. Jakarta: Salemba Empat.

Hery. 2017. Balanced Scored for Business. Jakarta: PT Grasindo.

Keown, Arthur J, et. al. 2008. Manajemen dan Keuangan. Jilid 1, Edisi Kesepuluh. Jakarta: Raja Grafindo Persada.

Hanafi, Mamduh dan Abdul Halim. 2016. Analisis Laporan Keuangan. Edisi V. Yogyakarta: UPP STIM YKPN.

Mursyidi. 2010. Akuntansi Biaya, Conventional Costing, Just In Time, dan Activity- Based Costing. Bandung: PT Refika Aditama.

Najmudin.2011. Manajemen Keuangan dan Akuntansi Syar'iyyah Modern. Edisi I. Yogyakarta: Andi.

Rudianto. 2009. Pengantar Akuntansi. Jakarta: Erlangga.

......... 2013. Akuntansi Manajemen Informasi untuk Pengambilan Keputusan Strategis. Jakarta: Erlangga.

Subramanyam, K.R dan John J. Wild. 2010. Analisa Laporan Keuangan: Financial Statement Analysis. Buku Satu. Edisi Sepuluh. Jakarta: Salemba Empat. 